\title{
Exposição ocupacional no transporte de materiais radioativos
}

\author{
Occupational exposure in the transportation of \\ radioactive materials
}

\author{
Jairo Wagner', Carla Júlia Segre Faiman²
}

DOI: http://dx.doi.org/10.11606/issn.2317-2770.v22i1p9-25

\begin{abstract}
Wagner J, Faiman CJS. Exposição ocupacional no transporte de materiais radioativos. Saúde, Ética \& Justiça. 2017;22(1):925 .

RESUMO: O uso pacífico da radiação tem se expandido a partir da segunda metade do século XX, com aplicação em campos como a indústria, a agricultura, a medicina e também para geração de energia nuclear. A partir dos dados documentais e de medidas de radiação emitida por remessas de material radioativo para hospitais, e utilizando projeções estatísticas e avaliação de hipóteses, o objetivo deste estudo é inferir as taxas de exposição à radiação dos motoristas envolvidos no transporte de produtos radioativos e verificar se elas estão em conformidade com os limites determinados pelas normas brasileira e internacional vigentes. Almeja-se, assim, estimar se há riscos de que trabalhadores nesta ocupação ultrapassem o limite imposto pela Comissão Nacional de Energia Nuclear (CNEN) para o indivíduo ocupacionalmente exposto (IOE) e, consequentemente, estejam sujeitos aos riscos que a exposição indevida à radiação possa ter sobre sua saúde. Com base em nossas medidas e projeções, realizadas a partir de dados de entrega de material para hospitais na cidade de São Paulo, verificamos que é provável que motoristas que estão atualmente na atividade ultrapassem os limites de exposição mensal preconizados para a preservação de sua saúde.
\end{abstract}

DESCRITORES: Exposição Ocupacional; Exposição à Radiação; Regulamentos.

\footnotetext{
1. Hospital Israelita Albert Einstein; curso de Medicina do Tráfego do Departamento de Medicina Legal, Ética Médica e Medicina Social e do Trabalho da Faculdade de Medicina da Universidade de São Paulo.

2. Departamento de Medicina Legal, Ética Médica e Medicina Social e do Trabalho da Faculdade de Medicina da Universidade de São Paulo.

Endereço para correspondência: Jairo Wagner. E-mail: jairowagner@einstein.br
} 


\section{INTRODUÇÃO}

$\mathbf{O}$ uso de materiais radioativos ou uso pacífico da radiação vem apresentando um crescente aumento em diferentes áreas do conhecimento desde a segunda metade do século XX. Durante este período de desenvolvimento, diversos tipos de aplicação surgiram gradualmente, promovendo o crescimento da utilização dos materiais radioativos na indústria, na agricultura, na Medicina e também para geração de energia nuclear.

Os isótopos radioativos (ou radioisótopos) têm como característica a emissão de radiação, isto é, eles desencadeiam um fenômeno de dispersão de energia, ou de partículas, que pode atravessar a matéria, interagir ou ser absorvida por ela ${ }^{1}$. Como a absorção dessa energia pelos tecidos vivos pode causar danos e até morte celular, existe uma grande preocupação com relação ao manuseio dos produtos radioativos para prevenir o surgimento de problemas de saúde decorrentes da exposição indevida à radiação.

Neste contexto, em 1956 foi aprovado o estatuto da AIEA (Agência Internacional de Energia Atômica), cujo papel era promover as aplicações pacíficas da energia atômica em prol da humanidade e, simultaneamente, proteger a sua utilização do uso nocivo ${ }^{2}$. Pensando na segurança das pessoas envolvidas no transporte desse tipo de material, a AIEA elaborou normas reguladoras, visando garantir a segurança desse tipo de atividade 3 .

No Brasil, o transporte de materiais radioativos obedece à Norma da Comissão Nacional de Energia Nuclear CNEN-NE-5.01 $1^{4}$, ainda em vigor, que tem como principal objetivo estabelecer, em relação ao transporte de materiais radioativos, requisitos de radioproteção e de segurança a fim de garantir um nível adequado de controle da eventual exposição de pessoas, bens e meio ambiente à radiação ionizante, compreendendo: a) especificações sobre materiais radioativos para transporte; b) seleção do tipo de embalado (conjunto composto pelo material radioativo e sua blindagem); c) especificação dos requisitos de projeto e de ensaios de aceitação de embalados; d) disposições pertinentes ao transporte propriamente dito e e) responsabilidades e requisitos administrativos.

Existe uma grande preocupação envolvendo a operação de transporte de produtos radioativos devido ao risco de rompimento da embalagem e, consequente, de dispersão do material para o ambiente. $\mathrm{O}$ expedidor de um produto radioativo é considerado o responsável pela segurança do transporte e sua responsabilidade inclui desde o preparo da expedição até elaboração e submissão à CNEN (Comissão Nacional de Energia
Nuclear) da documentação de porte obrigatório de todo o processo de transporte ${ }^{5}$.

\section{Embasamento científico}

A Radioatividade é a propriedade que alguns átomos, em configurações instáveis (como isótopos), têm de emitir radiação espontânea; este fenômeno refere-se à dispersão de energia ou partículas subatômicas. Hoje, esses isótopos radioativos (radioisótopos) podem ser utilizados em diversas áreas, tais quais:

- Medicina, para diagnóstico e terapia, como, por exemplo, tratamento de tumores;

- Agricultura, para conservação de alimentos;

- Indústria, para obtenção de energia nuclear ${ }^{1}$.

Neste estudo, especificamente, abordaremos o transporte dos materiais radioativos mais utilizados em Medicina Nuclear, avaliando remessas para hospitais. Os radioisótopos utilizados nessa área, sob a forma de radiofármacos, são, em grande parte, produzidos pelo Instituto de Pesquisas Energéticas e Nucleares - IPEN, da CNEN, em São Paulo ${ }^{3}$. Na documentação presente neste estudo, são abordados os seguintes radioisótopos:

- Tecnécio-99m (Tc-99m): utilizado para realização de cintilografias de diversos órgãos ou sistemas, como cérebro, pulmões, esqueleto, rins, fígado e vias biliares ${ }^{1}$.

- Iodo-131 (I-131): utilizado para diagnóstico e tratamento de lesões da tireoide e tumores neuroendócrinos ${ }^{1}$.

- Flúor-18 (F-18): utilizado na síntese de moléculas, entre elas a fluordesoxiglicose (FDG), principal radiofármaco para uso em tomografia por emissão de pósitrons (PET) ${ }^{6}$.

- Lutécio-177 (Lu-177): elemento radioativo emissor de radiação beta, utilizado para diagnóstico e tratamento de tumores neuroendócrinos, neoplasias da próstata e em radioimunoterapia entre outros ${ }^{7}$.

\section{Normas e especificações de transporte}

Toda atividade relacionada ao transporte de materiais radioativos necessita de um prévio planejamento e deve ser realizada em conformidade com a norma vigente. É necessário o armazenamento do material radioativo em embalagem específica, que forneça blindagem efetiva para reduzir a intensidade da exposição do trabalhador e de seus arredores à radiação. Este conjunto composto de material radioativo e blindagem é denominado embalado ${ }^{4}$. 


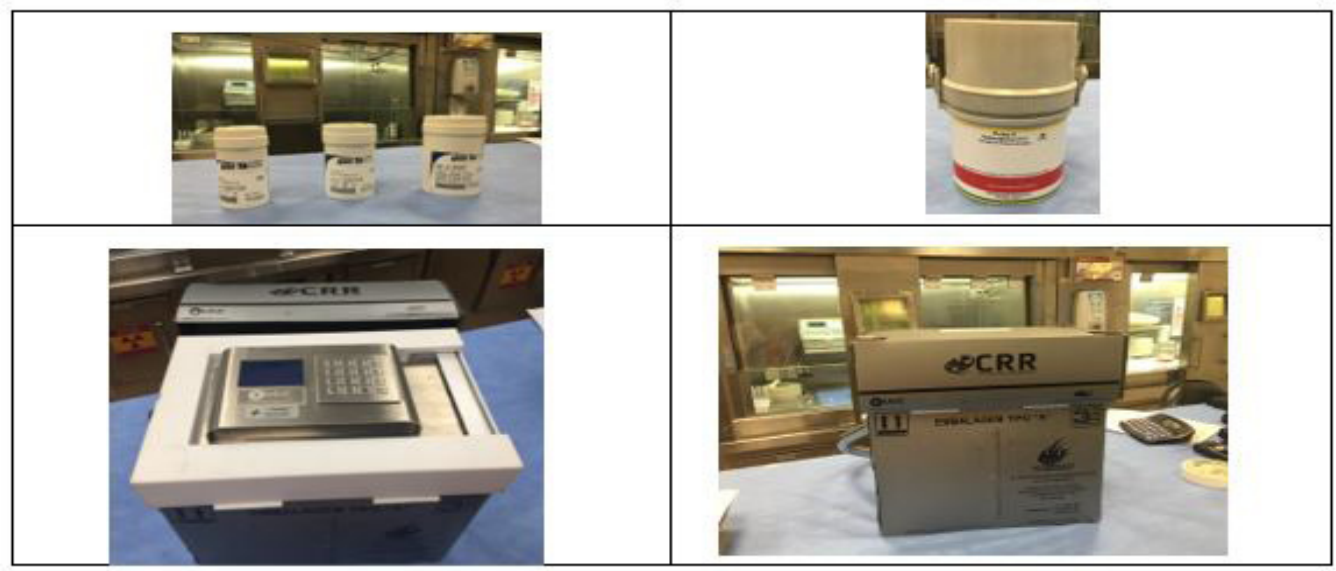

Figura 1. Diferentes tipos de embalagens utilizadas no transporte de material radioativo

A Norma CNEN-NE-5.01 de 01/08/1988 estabelece objetivos para garantir a segurança e a proteção no transporte de materiais radioativos, visando o controle de uma eventual exposição do material, compreendendo:

- Contenção do embalado no intuito de evitar a sua dispersão às pessoas, ao meio ambiente e a outros;

- Controle do nível de radiação externa, através de blindagem do embalado;

- Identificação/sinalização externa dos níveis de radiação;

- Impedir a exposição do embalado ao calor.

Todo embalado deve possuir identificação (duas etiquetas em lados opostos) que sinalize a presença do material radioativo em seu interior com o símbolo internacional de radiação ionizante (trifólio), salvo o do embalado exceptivo. As informações contidas na etiqueta de um embalado são suficientes para determinar o risco do material ${ }^{8}$.
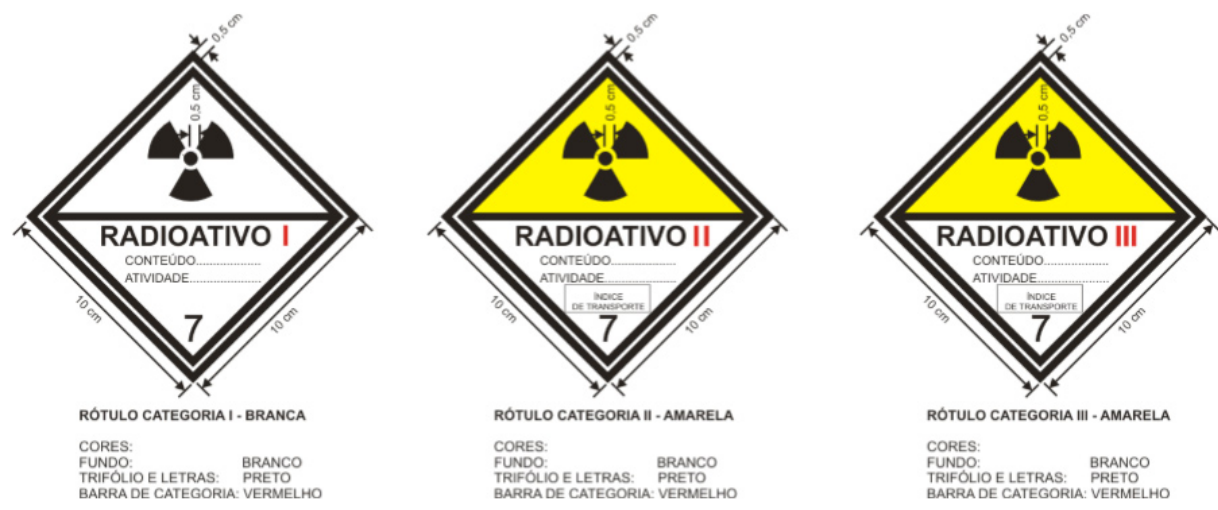

Fonte: Agência Internacional Energia Atômica (6)

Figura 2. Símbolo internacional de radiação ionizante (trifólio) e suas indicações

Em cada expedição, é obrigatória a apresentação dos seguintes documentos ${ }^{8}$ :

a) Envelope de Transporte;

b) Ficha de Emergência;

c) Ficha de Monitoração da Carga e do Veículo;

d) Declaração do Expedidor.

Uma declaração deve ser emitida pelo expedidor garantindo que, para cada remessa, o embalado esteja devidamente identificado e em condições seguras para o transporte. Devem também constar nos documentos todas as informações pertinentes, como nome e símbolo de cada radioisótopo, descrição completa, atividade máxima do conteúdo, categoria do embalado e marca das certificações de autoridade competente, além do nome do destinatário, endereço completo e a rota a ser seguida. Deve-se, ainda, acompanhar envelope de transporte padronizado pela NBR 7504, ficha de emergência padronizada pela NBR 7503 e ficha de monitoração do veículo. A Ficha de Monitoração da Carga e do Veículo e a Declaração do Expedidor são disponibilizadas em material eletrônico pela CNEN, e se encontram na seção ANEXOS, como, respectivamente, Anexo A e Anexo B ${ }^{8}$.

Quando um embalado for transportado por rodovia, deve-se estar de acordo com os requisitos abaixo: 
- O veículo deve possuir cobertura que impeça o acesso de pessoas não autorizadas ao seu interior;

- O embalado deve ficar fixo, sem possibilidade de deslocamento;

- Se o veículo não possuir paredes laterais na carroceria, pode-se apresentar as placas de aviso nos embalados, desde que estejam visíveis ${ }^{8}$;

A responsabilidade pelo transporte do embalado é do expedidor, bem como o cumprimento de outras normas estabelecidas pela CNEN-NE-5.01.

\section{Fatores de risco e efeitos da exposição indevida à radiação}

Embora experiências tenham mostrado que é baixa a probabilidade da ocorrência de acidentes envolvendo transporte de materiais radioativos, existem fatores de risco neste processo. No que diz respeito ao material propriamente dito e aos veículos utilizados para transporte, se houver qualquer tipo de rompimento ou danificação do embalado, há a possibilidade de vazamento e consequente emissão de significativas doses de radiação para o ambiente. Para evitar estas situações, há algumas providências adicionais para serem tomadas durante o transporte, tais como evitar rotas muito movimentadas e acondicionar adequadamente o material, no entanto, é indispensável o preparo correto e de acordo com as normas e especificações apresentadas na subseção anterior ${ }^{4}$.

Com relação aos efeitos da exposição indevida à radiação nuclear de um indivíduo, deve-se atentar ao fato de que a energia proveniente dos radioisótopos pode, na dependência da quantidade e do tempo de exposição, aumentar o risco de desenvolver danos à saúde. Em geral, tudo depende da quantidade e do tempo de exposição. As enfermidades mais comuns são catarata, queimaduras, doenças cardiovasculares, mau funcionamento de determinados órgãos, leucemia e até morte celular. Além disso, existem limites de uso da radiação em Medicina, pois uma quantidade elevada acumulada pela exposição a múltiplos exames, tais como radiodiagnósticos, cintilografias, to- mografia computadorizada e outros em que se utiliza este tipo de material, pode causar, tanto em pacientes como em funcionários, o desenvolvimento de alterações celulares. Todos estes limites são regulamentados pela CNEN, e devem ser seguidos rigorosamente, a fim de prevenir os efeitos causados pela exposição à radiação.

\section{OBJETIVOS}

A partir dos dados documentais e de medidas de radiação emitida por remessas e utilizando projeções estatísticas e avaliação de hipóteses, o objetivo deste estudo é inferir as taxas de exposição à radiação dos motoristas envolvidos no transporte de produtos radioativos e verificar se elas estão em conformidade com os limites determinados pelas normas brasileira e internacional vigentes. Almeja-se, assim, estimar as probabilidades de que trabalhadores nesta ocupação ultrapassem o limite imposto pela Comissão Nacional de Energia Nuclear (CNEN) para o indivíduo ocupacionalmente exposto (IOE) e, consequentemente, estejam sujeitos aos riscos provenientes da exposição indevida à radiação.

\section{MATERIAL E MÉTODOS}

\section{Levantamento de medidas de exposição de materiais radioativos}

As remessas de uma instituição que faz entregas de produtos radioativos para serviços de Medicina Nuclear na cidade de São Paulo foram monitorados no momento do recebimento seguindo os passos abaixo, aplicando o procedimento com detector Geiger-Muller para efetuar a medição:

1) As medidas foram feitas a partir de duas marcações de distância de um metro (uma marcação descrita como FONTE e outra como GEIGER). Essas marcações são referentes aos pontos onde foram posicionados os baldes com o material radioativo e o equipamento GeigerMuller, respectivamente.

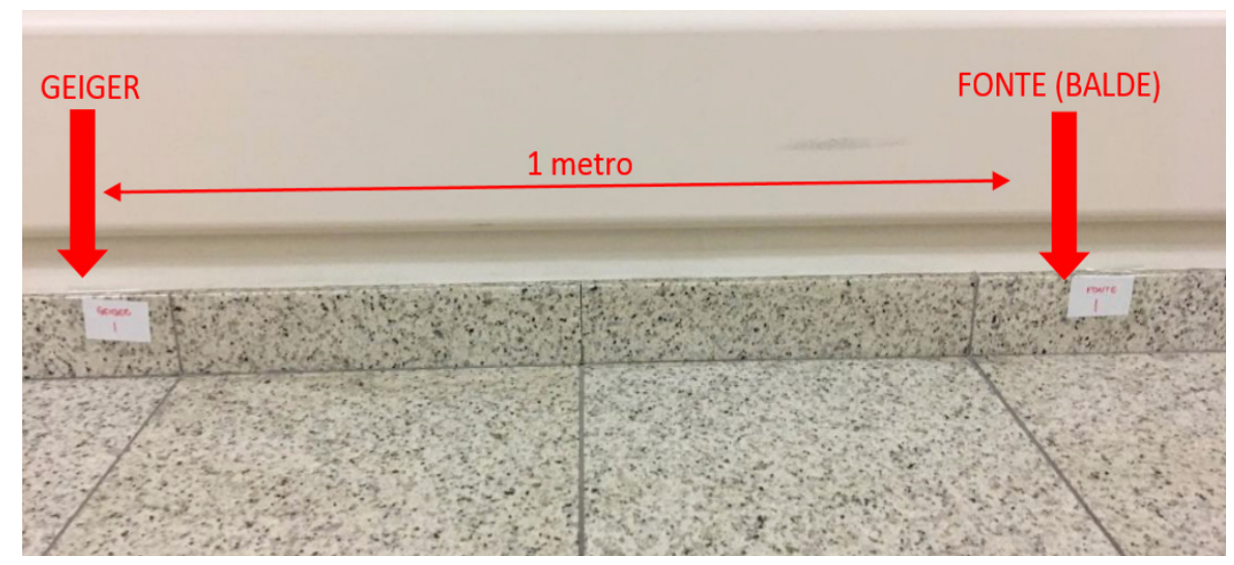

Figura 3. Posicionamento dos parâmetros de mediação 
Wagner J, Faiman CJS. Exposição ocupacional no transporte de materiais radioativos.

2) Tanto o balde quanto o Geiger foram posicionados aproximadamente na marca indicada, como mostra a imagem.

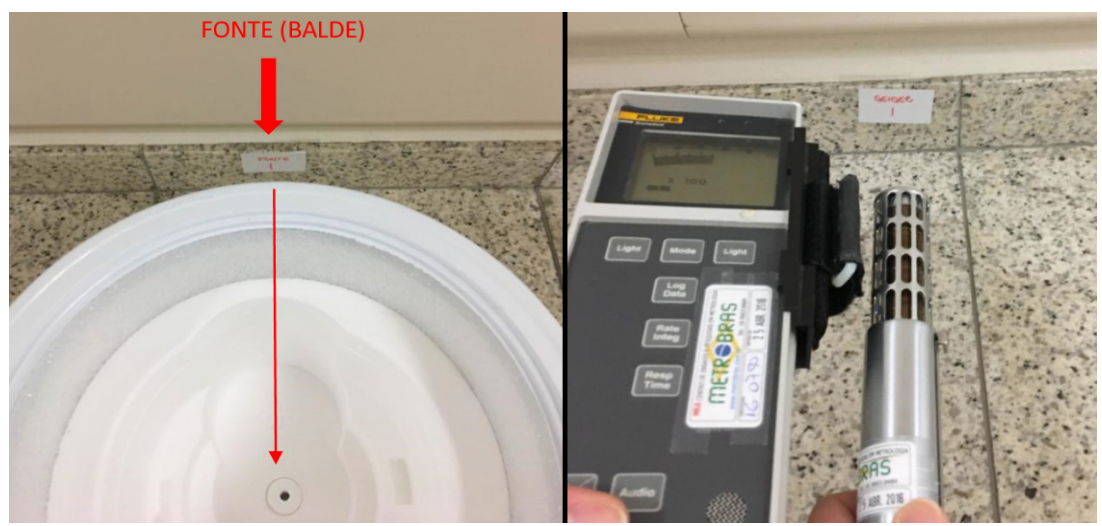

Figura 4. Posicionamento do balde e Geiger, respectivamente

3) Para efetuar a medida, basta posicionar o Geiger e aguardar a mesma estabilizar (lembrando que haverá pequenas oscilações).

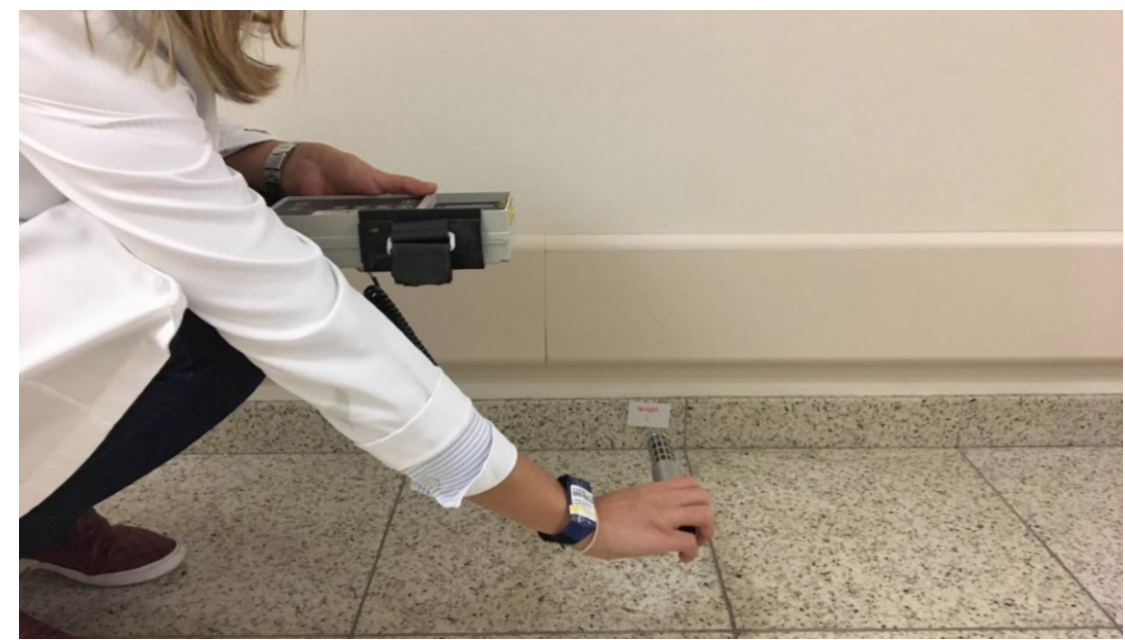

Figura 5. Procedimento de medição

4) As medidas obtidas devem ser anotadas numa planilha, em que deverão constar as seguintes informações:

a. Data: data da medida (caso a medida seja realizada em dia diferente da entrega, deve constar em observações);

b. Isótopo; c. Lote; (em mCi);

d. Atividade: quantidade de atividade do material Geiger;

e. Medida: medida em $\square \mathrm{Sv} / \mathrm{h}$, realizada com o

f. Observações: qualquer informação pertinente.

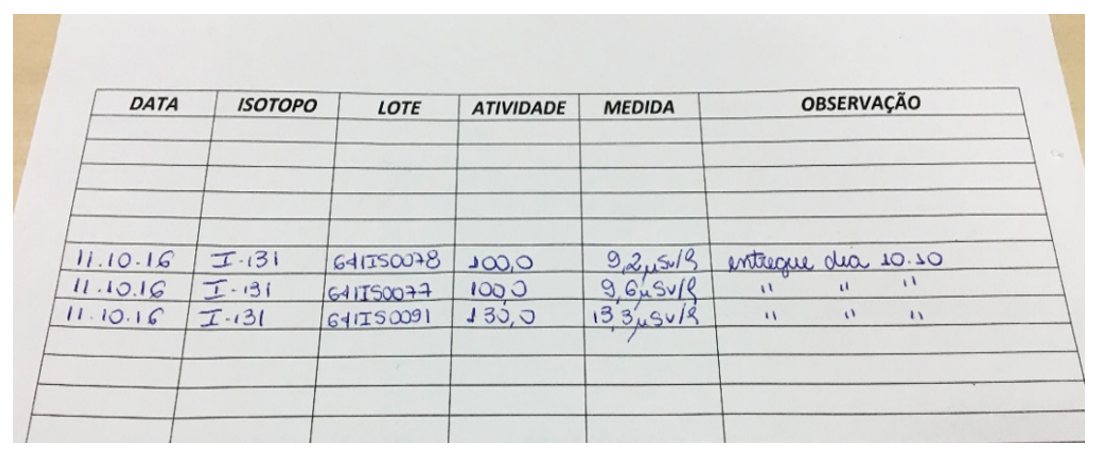

Figura 6. Planilha de anotações de resultados experimentais 


\section{Tabela de Dados Experimentais}

A partir das medidas obtidas através do procedimento apresentado, elaborou-se uma tabela de dados experimentais (que consta na seção ANEXOS como Anexo C). Essa Tabela é a base para as projeções estatísticas que avaliarão diversos casos hipotéticos, visando buscar uma forma de verificar e estimar situações nas quais o motorista pode ultrapassar o limite de exposição permitido pela Comissão Nacional de Energia Nuclear (CNEN).

\begin{tabular}{|c|c|c|c|c|c|c|c|}
\hline DATA & ISÓTOPO & $\begin{array}{l}\text { ATIVIDADE } \\
\text { RECEBIDA } \\
\text { (mCi) }\end{array}$ & $\begin{array}{c}\text { ATIVIDADE } \\
\text { RECEBIDA } \\
\text { (MBq) }\end{array}$ & $\begin{array}{c}\text { EXPOSIÇÃO } \\
\text { CALCULADA } \\
(\mathrm{mSV} / \mathrm{h})\end{array}$ & $\begin{array}{c}\text { EXPOSIÇÃO } \\
\text { MEDIDA } \\
\text { (mSV/h) }\end{array}$ & $\begin{array}{l}\text { ESTIMATIVA DOSE VIAGEM } \\
\text { DE } 45 \text { MINUTOS (mSv) }\end{array}$ & $\begin{array}{l}\text { SOMATÓRIO } \\
\text { MENSAL (mSv) }\end{array}$ \\
\hline $11 / 10 / 2016$ & $\mid-131$ & 114 & 4218 & 0,3222552 & 0,0076 & 0,0057 & \\
\hline $11 / 10 / 2016$ & $\mid-131$ & 113 & 4181 & 0,3194284 & 0,0079 & 0,005925 & \\
\hline $13 / 10 / 2016$ & $F-18$ & 398 & 14726 & 2,7257826 & 0,0052 & 0,0039 & \\
\hline $13 / 10 / 2016$ & $\mathrm{~F}-18$ & 284 & 10508 & 1,9450308 & 0,0037 & 0,002775 & \\
\hline $13 / 10 / 2016$ & Tc-99m & 2000 & 74000 & 2,4938 & 0,0202 & 0,01515 & \\
\hline $13 / 10 / 2016$ & Tc- $99 \mathrm{~m}$ & 600 & 22200 & 0,74814 & 0,0040 & 0,0030075 & \\
\hline $14 / 10 / 2016$ & $\mathrm{~F}-18$ & 420 & 15540 & 2,876454 & 0,0048 & 0,0036 & \\
\hline $14 / 10 / 2016$ & $\mathrm{~F}-18$ & 292 & 10804 & 1,9998204 & 0,0046 & 0,00345 & \\
\hline $14 / 10 / 2016$ & Tc-99m & 2800 & 103600 & 3,49132 & 0,0287 & 0,021525 & \\
\hline $17 / 10 / 2016$ & F-18 & 161 & 5957 & 1,1026407 & 0,0115 & 0,008625 & \\
\hline $18 / 10 / 2016$ & $\mathrm{~F}-18$ & 247 & 9139 & 1,6916289 & 0,0047 & 0,003525 & \\
\hline $18 / 10 / 2016$ & $\mathrm{~F}-18$ & 137 & 5069 & 0,9382719 & 0,0026 & 0,00195 & \\
\hline
\end{tabular}

Figura 7. Parcela da tabela de dados presente na seção ANEXOS

A Figura 7, amostra parcial da Tabela, trazendo dados utilizados para estimar e inferir as taxas de exposição à radiação. As colunas desta tabela indicam: MEDIDA

1) DATA: Informa a data da realização da

2) ISÓTOPO: Informa qual o Isótopo recebido.

3) ATIVIDADE RECEBIDA (mCi): Informa a quantidade de atividade recebida pelo hospital em milicuries.

4) ATIVIDADE RECEBIDA (MBq): Informa a quantidade de atividade recebida pelo hospital em megabecquerel (OBS: $1 \mathrm{mCi}=37 \mathrm{MBq})$.

5) EXPOSIÇÃO CALCULADA: Informa a exposição calculada em milisievert ( $\mathrm{mSv}$ ) em uma hora, teoricamente referente a uma atividade recebida a um metro de distância. Esse cálculo teórico NÃO considera a blindagem à qual os materiais transportados foram submetidos e, portanto, é um valor muito maior do que a exposição medida. Cada fornecedor e cada tipo de isótopo possui blindagens diferentes de acordo com a característica física do material.

6) EXPOSIÇÃO MEDIDA: Informa a quantidade de exposição medida em milisievert $(\mathrm{mSv})$ em uma hora, calculada através do procedimento em que se utiliza o equipamento Geiger-Muller, explicado anteriormente $(O B S: 1 \square S v / h=0,001 \mathrm{mSv} / \mathrm{h})$.

7) ESTIMATIVA DOSE VIAGEM DE 45 MINUTOS: Informa a estimativa de exposição do trabalhador durante o transporte, considerando um trajeto de 45 minutos entre o fornecedor e o hospital (em mSv).

8) SOMATÓRIO MENSAL: Informa a soma total de exposição sofrida pelo motorista levando em consideração apenas as remessas deste único hospital (em mSv).

Neste estudo, descreveremos os materiais radioativos mais comercializados e transportados no Brasil e quais os fatores de risco envolvidos neste transporte, além de apresentarmos exemplos de dados entregues com cada remessa do produto do local de origem ao destinatário. A partir desta documentação, mediremos a taxa de exposição à radiação de todas as remessas de materiais radioativos entregues em um hospital. E, fazendo uso dessas medidas, utilizaremos de ferramentas teóricas, hipotéticas e estatísticas para inferir e estimar as taxas de exposição à radiação do motorista que transporta, descarrega e entrega este tipo de produto.

\section{RESULTADOS}

\section{Limites de dosagens e considerações}

De acordo com a Comissão Nacional de Energia Nuclear (CNEN), existem limites de exposição à radiação para indivíduos do público e indivíduos ocupacionalmente

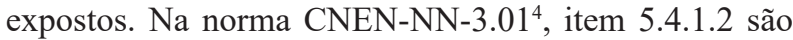
apresentados os limites e definições:

"A exposição normal dos individuos deve ser restringida de tal modo que nem a dose efetiva nem a dose equivalente nos órgãos ou tecidos de interesse, causadas pela possivel combinação de exposições originadas por práticas autorizadas, excedam o limite de dose especificado na tabela a seguir, salvo em circunstâncias especiais, autorizadas pela CNEN. Esses limites de dose não se aplicam às exposições médicas" 


\begin{tabular}{|c|c|c|c|}
\hline \multicolumn{3}{|c|}{ Limites de Dose Anuais } \\
\hline Grandeza & Órgão & $\begin{array}{c}\text { Indivíduo ocupacionalmente } \\
\text { exposto }\end{array}$ & Indivíduo do público \\
\hline \multirow{2}{*}{ Dose efetiva } & Corpo inteiro & $20 \mathrm{mSv}$ & $1 \mathrm{mSv}$ \\
\hline \multirow{2}{*}{ Dose equivalente } & Cristalino & $20 \mathrm{mSv}$ & $15 \mathrm{mSv}$ \\
& Pele & (Alterado pela Resolução CNEN 114/2011) & $50 \mathrm{mSv}$ \\
\cline { 2 - 4 } & Mãos e pés & $500 \mathrm{mSv}$ & -- \\
\cline { 2 - 4 } & & 500 & 5 \\
\hline
\end{tabular}

Figura 8. Tabela de limites de dosagens impostos pela $\mathrm{CNEN}^{*}$

*Disponível em: http://appasp.cnen.gov.br/seguranca/normas/pdf/Nrm301.pdf, p.13.

A Figura 8 mostra os limites de dose permitidos por norma. Todo trabalhador que se expõe à radiação ionizante provinda do material radioativo é denominado indivíduo ocupacionalmente exposto (IOE), ou seja, o limite de dose anual para corpo inteiro é de $20 \mathrm{mSv}$. Os dosímetros de uso individual utilizados para essa leitura são trocados mensalmente e, portanto, podemos dizer que há um limite mensal de 1,67 mSv (20 mSv divididos por 12 meses consecutivos). São definidos valores ainda mais baixos para controle da exposição do trabalhador; o chamado de nível de investigação possui valor de $1,0 \mathrm{mSv}$. Quando o IOE atinge esse limite é feita uma avaliação e são definidas ações para diminuir a exposição. Além disso, o limite de $20 \mathrm{mSv}$ anual é a média de 5 anos consecutivos, sendo que em um único ano o IOE pode chegar a receber $50 \mathrm{mSv}$, sendo obrigatório garantir que nos anos seguintes a média de $20 \mathrm{mSv}$ será mantida. No entanto, para fins estatísticos, será considerada uma dosagem mensal igual para todos os meses, levando em consideração este limite de 1,67 mSv. Além disso, devese atentar a algumas considerações e observações sobre as informações apresentadas nas seções e subseções anteriores e na tabela identificada como Anexo C:

1) As remessas presentes na tabela são feitas por diferentes motoristas, portanto, não representam a dose de um único trabalhador. Porém, para fins de análise estatística, os valores demonstrados na tabela serão considerados como sofridos por um único trabalhador;

2) O somatório mensal refere-se a apenas um hospital. No entanto, os motoristas entregam em várias instituições e isso quer dizer que essa dose estimada é apenas uma parcela da exposição total sofrida pelos motoristas num mês;

3) As medidas realizadas correspondem a um hospital relativamente perto de um dos principais fornecedores, ou seja, o tempo de transporte de 45 min pode variar para outras instituições e, portanto, o motorista pode receber doses diferentes das apresentadas nestas estimativas;
4) Para os cálculos de exposição teórica foi considerada a distância fixa de 1 metro entre o motorista e o material, no entanto esta distância sofre oscilações, como em processos de carregamento e descarregamento.

\section{Projeções Estatísticas}

De acordo com as observações e considerações anteriormente apresentadas, as projeções estatísticas visam encontrar maneiras de se estimar, verificar e visualizar situações nas quais não é possível saber exatamente se um indivíduo pode ultrapassar o limite imposto pela CNEN de exposição a materiais radioativos. Como existem muitas variáveis envolvidas, não é possível construir expressões matemáticas ou regras que demonstrem precisamente esses limites, mas a análise estatística é capaz de traçar estimativas, que podem servir como base para tal objetivo.

\section{Análise de situações hipotéticas de quantidade de material constante e tempo de transporte variável}

Vamos supor a seguinte situação hipotética utilizando a tabela Anexo C: um único motorista entrega a mesma quantidade de atividade de cada isótopo para três instituições diferentes, no período de 11/10 até 10/11 ( $1^{\circ}$ mês). O Hospital A fica a 45 minutos do fornecedor, o Hospital B a uma hora e o Hospital C a uma hora e meia.

De acordo com a tabela, o somatório mensal de exposição recebida pelo motorista ao entregar todas as remessas ao Hospital A é aproximadamente de $0,39 \mathrm{mSv}$ (23,4\% do limite mensal permitido). Agora, tomando como base a coluna de EXPOSIÇÃO MEDIDA, que informa a quantidade de exposição de cada remessa por hora, podemos obter o somatório mensal de exposição recebida pelo trabalhador ao entregar todos estes pedidos 
ao Hospital B $(0,52 \mathrm{mSv}-31,2 \%$ do limite mensal permitido). Por fim, para estimar a exposição sofrida ao entregar as remessas ao Hospital C, podemos estabelecer uma relação simples com os valores do Hospital B. Enquanto em uma hora se calculou cerca de 0,52 $\mathrm{mSv}$, em $1 \mathrm{~h} 30$ se calcularia $0,78 \mathrm{mSv}(0,52 * 1,5)$, que corresponde a $46,8 \%$ do limite mensal permitido. Assim, fazendo a soma da exposição dos três hospitais, obtémse aproximadamente 1,69 mSv (ultrapassando em 1,4\% o limite mensal). Mas se fizermos exatamente a mesma análise no período de $11 / 11$ até $09 / 12$ ( $2^{\circ}$ mês), obteremos uma soma de $1,34 \mathrm{mSv}$ (80,4\% do limite mensal). Assim, do período de $11 / 10$ até $09 / 12$ (2 meses) o valor seria de 3,03 mSv, representando uma exposição média mensal dentro dos limites, de 1,52 mSv (91,2\%).

Agora, se considerarmos apenas os valores referentes às entregas ao Hospital $\mathrm{B}$ (que fica a uma hora do fornecedor) para estes dois meses, obteremos os seguintes valores de exposição para volume total das remessas: $0,52 \mathrm{mSv} / \mathrm{h}$ no primeiro mês e $0,41 \mathrm{mSv} / \mathrm{h}$ no segundo mês, retornando uma média de $0,47 \mathrm{mSv} / \mathrm{h}$. Essa média representa a exposição sofrida por hora, referente à média da quantidade de atividade dos materiais nestes dois meses.

Neste tipo de hipótese, o volume total de exposição depende apenas do tempo, sendo uma relação de proporcionalidade direta. Desta forma, considerando a quantidade de remessas médias e de material radioativo sempre constantes, é possível afirmar que se todos os trajetos a um número qualquer de hospitais somassem aproximadamente $3 \mathrm{~h} 32 \mathrm{~min} 46 \mathrm{~s}$, o limite mensal seria atingido, e o trabalhador teria que atender a medidas para diminuir a exposição, tais como o rodízio com outros trabalhadores, garantindo que a somatória anual não fosse atingida.

Tabela 1. Evolução da exposição mensal média por hora em função do tempo (quantidade de atividade constante)

\begin{tabular}{c|c}
\hline $\begin{array}{c}\text { Soma do tempo de } \\
\text { todos os trajetos }(\mathbf{h})\end{array}$ & $\begin{array}{c}\text { Exposição mensal } \\
\text { média por hora }(\mathbf{m S v} / \mathbf{h})\end{array}$ \\
\hline 1 & 0,47 \\
\hline 1,5 & 0,71 \\
\hline 2 & 0,94 \\
\hline 2,5 & 1,18 \\
\hline 3 & 1,41 \\
\hline 3,5 & 1,65 \\
\hline $\mathbf{3 , 5 4 6 1}$ & $\mathbf{1 , 6 7}$ \\
\hline 4 & 1,88 \\
\hline
\end{tabular}

Este tipo de análise é relativamente simples, uma vez que considera apenas a variação do número de hospitais e do tempo de trajeto do fornecedor às instituições. Como na maioria dos casos a quantidade de material recebido pelas instituições não é a mesma, este tipo de projeção, apesar de apresentar uma informação importante, representa apenas uma situação ideal e não é adequada para servir como base para a maioria das estimativas.

Outra importante variável que também não foi considerada é a questão do decaimento dos materiais radioativos. Alguns radioisótopos possuem a característica física de meia-vida curta (rápido decaimento). $\mathrm{O}$ fornecedor envia uma atividade maior de material radioativo para garantir que no momento da entrega no hospital seja recebida a quantidade solicitada. Isso significa que durante o percurso, para alguns tipos de materiais, a exposição é maior do que a medida.

Análise de situações hipotéticas de quantidade de material variável e tempo de transporte constante

Agora, vamos avaliar outro tipo de hipótese, na qual consideraremos um tempo de trajeto sempre constante de uma hora a apenas um hospital, mas de quantidade de material variável. Para tanto, necessitamos:

1) Estimar a eficiência das blindagens utilizadas;

2) Estimar a taxa de exposição real de um isótopo no tempo de uma hora;

3) Modelar expressões estatísticas teóricas para ilustrar essas estimativas.

\section{Estimativa da eficiência média da blindagem para cada isótopo}

A partir da tabela exposta no Anexo C, podemos inferir as taxas de eficiência das blindagens utilizadas em cada isótopo, fazendo uma comparação simples entre a exposição teórica calculada (sem blindagem) e a exposição medida. Para efetuar essas inferências, vamos:

1) Obter da tabela todas as remessas referentes a cada isótopo e agrupá-las, para avaliar cada produto separadamente.

2) No grupo de um determinado isótopo, cada remessa possui um valor teórico de exposição sem blindagem (exposição calculada - EC) e um valor experimental medido através do uso do equipamento Geiger-Muller (exposição medida - EM). Para cada remessa, vamos obter uma razão entre a EM e a EC, que será identificada como porcentagem relativa de exposição real (PRER), dada por:

PRER $=\frac{E M}{E C} * 100 \%$

3) A média aritmética simples de todas as PRER de um grupo de isótopo determina a taxa de exposição real média (TERM) deste isótopo, isto é, a taxa de 
exposição efetivamente recebida pelo motorista em relação a este radioisótopo, levando em consideração a blindagem. A partir dela, podemos obter a Eficiência Média da Blindagem (EMB), dada por:

$E M B=100 \%-T E R M$

Através deste procedimento, obtemos as seguintes taxas de eficiência da blindagem:

Tabela 2. Estimativa da eficiência da blindagem para cada isótopo

\begin{tabular}{c|c}
\hline Isótopo & $\begin{array}{c}\text { Eficiência Média da Blindagem } \\
\text { (EMB) }\end{array}$ \\
\hline F-18 & $99,54 \%$ \\
\hline Tc-99m & $99,16 \%$ \\
\hline I-131 & $97,25 \%$ \\
\hline Lu-177 & $92,51 \%$ \\
\hline
\end{tabular}

Considerações:

1) Para o isótopo I-131 foram desconsiderados 2 outliers nesta estimativa.

\section{Estimativa da taxa de exposição real de cada isótopo em 1 hora}

Sabendo das estimativas da eficiência média das blindagens para cada isótopo, podemos inferir qual a quantidade aproximada de exposição para diferentes volumes de material radioativo por hora, isto é, podemos estimar, sabendo a quantidade de atividade de um material, a exposição real sofrida. Primeiramente, deve-se fazer o cálculo da exposição teórica de uma quantidade de atividade de um determinado isótopo. Essa informação é apresentada na tabela Anexo C, sendo identificada como exposição calculada (EC) e dada por:

$$
E C=37 x * \gamma \quad(\mathrm{mSv} / \mathrm{h})
$$

Onde: (mCi);

$\mathrm{x}$ é a quantidade de atividade do isótopo analisado

$\gamma$ é a exposição recebida por unidade de atividade deste isótopo em $\mathrm{MBq}$ a uma distância de 1 metro (mSv/ MBq.h).

Os valores de gama( $\gamma$ ) (Gamão) são constantes para cada tipo de isótopo abrangido no estudo e podem ser consultados na seguinte tabela auxiliar:

Tabela 2.1. Valores constantes $\gamma$ para cada isótopo*

\begin{tabular}{c|c}
\hline \multicolumn{1}{c|}{ Isótopo } & $\gamma(\mathbf{m S v} / \mathbf{M B q} \cdot \mathbf{h})$ a $\mathbf{1 0 0}$ centímetros \\
\hline F-18 & $1,85 \mathrm{E}-04$ \\
Tc-99m & $3,37 \mathrm{E}-05$ \\
I-131 & $7,64 \mathrm{E}-05$ \\
Lu-177 & $7,64 \mathrm{E}-06$ \\
\hline
\end{tabular}

Por fim, para estimar a exposição real (ER) recebida pelo motorista para cada isótopo, a partir destes cálculos teóricos, basta aplicar a estimativa da eficiência média da blindagem (EMB) sobre o valor da exposição calculada (EC) obtida, modelando a expressão:

$E R=E C *(100 \%-E M B) \quad(\mathrm{mSv} / \mathrm{h})$

Tabela 3. Estimativas para o valor de exposição real de $1 \mathrm{mCi}$ de atividade de cada isótopo, sofrida durante 1 hora

\begin{tabular}{c|c|c|c|c}
\hline Isótopo & $\gamma(\mathbf{m S v} / \mathbf{M B q} \cdot \mathbf{h})$ & EC para $\mathbf{1} \mathbf{~ m C i}$ de atividade $(\mathbf{m S v} / \mathbf{h})$ & EMB & ER para 1 $\mathbf{~ m C i ~ d e ~ a t i v i d a d e ~}(\mathbf{m S v} / \mathbf{h})$ \\
\hline F-18 & $1,85 \mathrm{E}-04$ & $6,85 \mathrm{E}-03$ & $99,54 \%$ & $\mathbf{3 , 1 5 E - 0 5}$ \\
Tc-99m & $3,37 \mathrm{E}-05$ & $1,25 \mathrm{E}-03$ & $99,16 \%$ & $\mathbf{1 , 0 5 E}-\mathbf{0 5}$ \\
$\mathrm{I}-131$ & $7,64 \mathrm{E}-05$ & $2,83 \mathrm{E}-03$ & $97,25 \%$ & $\mathbf{7 , 7 7 E - 0 5}$ \\
Lu-177 & $7,60 \mathrm{E}-06$ & $2,81 \mathrm{E}-04$ & $92,51 \%$ & $\mathbf{2 , 1 1 E - 0 5}$ \\
\hline
\end{tabular}

Resumidamente, na tabela acima, a última coluna indica o valor estimado de exposição REAL de $1 \mathrm{mCi}$ de atividade de um determinado tipo de isótopo durante 1 hora.

\section{Modelagem de expressão matemática}

Considerando uma situação em que um único motorista entrega somente os produtos citados para apenas um hospital num período de um mês, e que o tempo de trajeto é sempre de uma hora, podemos modelar expressões gerais para ilustrar as estimativas anteriores, demonstrando a quantidade de exposição recebida em
$B=\sum_{i=1}^{4}\left(E R_{i} * x_{i}\right) \quad(m S \mathrm{Sw}) \mathrm{m}$

função das atividades expedidas:

Onde:

B é a exposição real total em um mês;

Os números de 1 a 4 representam cada um dos quatro isótopos abrangidos neste estudo;

$\mathrm{ER}_{\mathrm{i}}$ é a exposição real por $\mathrm{mCi}$ de atividade de um determinado isótopo (em $\mathrm{mSv}$ );

$\mathrm{x}_{\mathrm{i}}$ é o total da quantidade de atividade do determinado isótopo expedida durante um mês (em $\mathrm{mCi})$. 


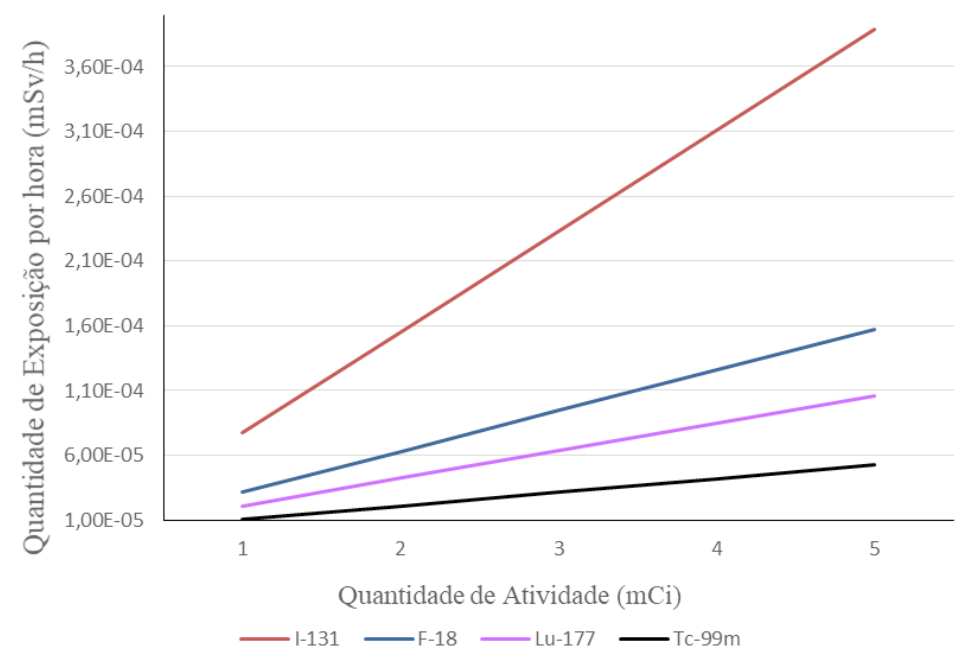

Figura 9. Evolução da exposição em função da quantidade de atividade de cada isótopo

Embora a expressão forneça uma boa forma de estimativa da exposição real dos materiais radioativos, ela ainda não é totalmente adequada, uma vez que existe a possibilidade de variação do número de instituições de entrega e tempo de trajeto entre o fornecedor e as mesmas, não consideras nesta subseção.

Análise de situações hipotéticas de quantidade de material e tempo de transporte variáveis

Para fins de análise mais aprofundada, vamos, por fim, trabalhar com as variações dos três tipos, visando obter uma expressão geral a qual possa ser utilizada para estimar e verificar valores para a exposição total mais próximos da realidade. As variações podem ser as seguintes: radioativos;

1) Quantidade de atividade de materiais

2) Número de instituições de entrega;

3) Tempo de trajeto para cada instituição de entrega.

Inicialmente, a partir da equação 5 , que fornece o valor de B (exposição real total para tempo constante), podemos acrescentar a presença da variação do tempo de trajeto. Ao fazer isso, estaremos criando uma entidade $\left(\mathbf{B}_{\mathbf{h}}\right)$ para representar a exposição real total de um determinado hospital, para o qual o tempo de trajeto pode ser diferente de 1 hora:

$B_{h}=\left(\sum_{i=1}^{4}\left(E R_{i} * x_{i}\right)\right) * T_{h}$
Onde:

$B_{h}$ é o valor de exposição real total de um determinado hospital;

$\mathrm{T}_{\mathrm{h}}$ é o tempo de trajeto entre o fornecedor e o hospital (em horas).

Agora, levando em consideração a possibilidade de variação da quantidade de instituições, podemos abranger ainda mais essa expressão, obtendo finalmente valores para exposição real total (E) que incluam a presença dos três tipos de variação citados:

$E=\sum_{h=1}^{n}\left(\left(\sum_{i=1}^{4}\left(E R_{i} * x_{i}\right)\right)_{h} * T_{h}\right)$

$(\mathrm{msV})$

Onde:

Os números de 1 a $n$ representam o número de hospitais;

E é o valor de exposição real total de todos os $n$ hospitais.

Como $\mathbf{E}$ representa o valor da exposição real total em um mês sofrida por um trabalhador considerando todas as variáveis, podemos afirmar que, para que não se ultrapasse o valor permitido pela CNEN, a soma anual dos valores encontrados para cada mês por esta expressão deve ser sempre menor do que $20 \mathrm{mSv}$, mesmo que em alguns meses se ultrapasse a quantidade de 1,67 mSv.

Como não há dados experimentais suficientes para mensurar a quantidade de exposição real de um motorista durante entregas em vários hospitais, utilizamos a formulação de situações hipotéticas analisadas pelas ferramentas propostas na seção anterior, majoritariamente 
Wagner J, Faiman CJS. Exposição ocupacional no transporte de materiais radioativos.

a Equação 7.

Assim, inicialmente, considerando uma situação hipotética na qual um único motorista faz as seguintes entregas de remessas no período de 1 mês:

Tabela 4. Situação hipotética 1: Remessas entregues por um único trabalhador no período de $01 /$ jan a $31 /$ jan

\begin{tabular}{l|c|c|c}
\hline Instituição & Isótopo & Quantidade total de Atividade (mci) & Tempo de transporte (h) \\
\hline Hospital A & F-18 & 2324 & 1 \\
\hline Hospital A & Tc-99m & 12930 & 1 \\
\hline Hospital A & I-131 & 674 & 1 \\
\hline Hospital A & Lu-177 & 508 & 1 \\
\hline Hospital B & F-18 & 3882 & 1,5 \\
\hline Hospital B & Tc-99m & 15440 & 1,5 \\
\hline Hospital B & I-131 & 1233 & 1,5 \\
\hline Hospital B & Lu-177 & 2685 & 1,5 \\
\hline Hospital C & F-18 & 1115 & 1,25 \\
\hline Hospital C & Tc-99m & 9890 & 1,25 \\
\hline Hospital C & I-131 & 3606 & 1,25 \\
\hline Hospital C & Lu-177 & 866 & 1,25 \\
\hline
\end{tabular}

AEquação 7 retorna um valor de aproximadamente $1,47 \mathrm{mSv}$ de exposição real sofrida pelo motorista durante o período retratado nesta situação. Agora, vamos considerar uma segunda hipótese, em que o motorista começa a entregar a mais uma instituição e a demanda dos outros hospitais aumenta:

Tabela 5. Situação hipotética 2: Remessas entregues por um único trabalhador no período de $01 / \mathrm{fev}$ a $28 / \mathrm{fev}$

\begin{tabular}{l|c|c|c}
\hline Instituição & Isótopo & Quantidade total de Atividade (mci) & Tempo de transporte (h) \\
\hline Hospital A & F-18 & 3292 & 1 \\
\hline Hospital A & Tc-99m & 13884 & 1 \\
\hline Hospital A & I-131 & 750 & 1 \\
\hline Hospital A & Lu-177 & 769 & 1,5 \\
\hline Hospital B & F-18 & 5270 & 1,5 \\
\hline Hospital B & Tc-99m & 14935 & 1,5 \\
\hline Hospital B & I-131 & 2356 & 1,5 \\
\hline Hospital B & Lu-177 & 3104 & 1,25 \\
\hline Hospital C & F-18 & 2324 & 1,25 \\
\hline Hospital C & Tc-99m & 9930 & 1,25 \\
\hline Hospital C & I-131 & 1532 & 1,25 \\
\hline Hospital C & Lu-177 & 903 & 2 \\
\hline Hospital D & F-18 & 3450 & 2 \\
\hline Hospital D & I-131 & 1124 & 2 \\
\hline Hospital D & Lu-177 & 524 & \\
\hline
\end{tabular}


Agora, nesta segunda hipótese, o valor obtido para a exposição total à radiação foi de aproximadamente 1,89 mSv. Claramente, é um valor bem maior do obtido no primeiro mês, devido ao aumento da demanda e principalmente devido à existência do Hospital D (que é consideravelmente mais longe do que os outros três). Embora o volume de atividade entregue a esse último seja relativamente pequeno, o tempo de exposição potencializa a radiação recebida pelo motorista ao transportar esses radioisótopos. Se desconsiderássemos o Hospital D nesta hipótese, obteríamos um valor de exposição total próximo de $1,48 \mathrm{mSv}$, significando que somente as remessas neste trajeto totalizam cerca de 0,41 $\mathrm{mSv}$ de radiação (maior do que a soma do Hospital A nesta hipótese, que corresponde a cerca de $0,32 \mathrm{mSv}$, apesar da grande diferença de quantidade de atividade expedida).

Outras hipóteses, envolvendo outros valores de variáveis, são possíveis e muitas podem representar situações reais. As duas situações retratadas nesta seção são perfeitamente possíveis de acontecer, uma vez que nenhuma explora quantidades irreais de material expedido, tempo de trajeto ou quantidade de instituições. Por fim, vale ressaltar que mesmo na segunda hipótese o valor de exposição total ter ultrapassado o limite mensal de 1,67 mSv, isso não viola o limite imposto pela CNEN, desde que a soma de todos os meses em 1 ano não exceda os $20 \mathrm{mSv}$. Contudo, uma média mensal deste valor de exposição à radiação pode, sim, ultrapassar o limite estabelecido por norma.

\section{DISCUSSÃO}

Primeiramente, para que o objetivo deste estudo seja, de fato, concluído, e para que as ferramentas matemáticas obtidas através da análise estatística funcionem corretamente, deve-se fazer um levantamento dos dados a serem analisados, que contenha, necessariamente:

- Data de entrega da remessa;

- Quantidade de instituições para as quais o motorista entrega; instituição;

- Tempo de trajeto entre o fornecedor e cada

- Quantidade de atividade de cada isótopo entregue a cada hospital.

Essas variáveis são indispensáveis para realizar a estimativa da radiação total recebida pelo trabalhador.
Além disso, todos os dados devem ser anotados utilizandose os formulários existentes nas normas vigentes e seguidas rigorosamente, pois este controle no transporte de materiais radioativos influenciará diretamente na segurança dos envolvidos no processo.

Como observado nos resultados da seção anterior, pode-se dizer que há uma relação direta entre o tempo de exposição a determinado material radioativo e a quantidade (atividade) do mesmo. Por análise das expressões 5,6 e 7 é possível concluir que o valor de exposição total seria dobrado se a quantidade de material fosse também dobrada. Podendo-se afirmar o mesmo em relação ao tempo de trajeto. Apesar disso, em situações reais, o tempo de trajeto influencia muito mais do que a variação da quantidade de material, já que é muito mais viável que haja uma duplicação no tempo de trajeto do que no volume de radioisótopos transportados. Seguindo a linha de raciocínio, é possível afirmar que o número de instituições influencia tanto na quantidade de material quanto no tempo de exposição, sendo uma variável que amplifica ambas, e, de fato, possui enorme impacto no valor de exposição total que o motorista recebe. Estas inferências demonstram como este valor é muito variável e sensível, sendo possível que muitos trabalhadores deste setor ultrapassem o limite anual de $20 \mathrm{mSv}$.

\section{CONCLUSÃO}

Com o auxílio dessas inferências estatísticas e análises de situações hipotéticas, podemos estimar as taxas médias mensais de exposição dos trabalhadores a partir de informações primárias, destacando a existência de casos em que o limite mensal é ultrapassado. Para tanto, o levantamento simples destes dados e a utilização da Equação 7 são necessários para verificar se o indivíduo está submetido a doses anuais de exposição à radiação maiores do que a permitida.

Desta forma, com os dados apresentados neste estudo e com a análise estatística realizada, podemos concluir que as normas e os quesitos regulatórios que regem o transporte de materiais radioativos atendem aos níveis de segurança e proteção dos envolvidos no processo de manipulação do material radioativo, da saída do expedidor até o cliente, desde que rigorosamente seguidas, tanto por parte do expedidor quanto do trabalhador e seu entendimento quanto ao papel de risco assumido neste processo. 
Wagner J, Faiman CJS. Exposição ocupacional no transporte de materiais radioativos.

ANEXO A*

Ficha de monitoração da carga e do veículo rodoviário

\begin{tabular}{|c|c|c|c|}
\hline \multicolumn{4}{|c|}{ FICHA DE MONITORAÇÃO DA CARGA E DO VEIĆCULO RODOVIÁRIO } \\
\hline \multicolumn{4}{|c|}{ MONITORAÇĀO DA CARGA } \\
\hline \multirow{2}{*}{$\begin{array}{c}\text { EMBALADO } \\
\text { (TIPO) }\end{array}$} & \multirow[t]{2}{*}{ RÓTULO } & \multicolumn{2}{|c|}{$\begin{array}{c}\text { TAXA DE EXPOSIÇĀO } \\
\mu \mathrm{Ci} / \mathrm{Kg} \mathrm{h} \\
\end{array}$} \\
\hline & & NA SUPERFICIE & A 1 METRO \\
\hline & & & \\
\hline & & & \\
\hline & & & \\
\hline & & & \\
\hline
\end{tabular}

\begin{tabular}{|l|l|l|l|l|}
\hline \multirow{2}{*}{ PONTOS } & \multicolumn{3}{|c|}{ TAXA DE EXPOSIÇÃO } & \multirow{2}{*}{ ESPECIFICAÇÃO DO LOCAL } \\
\cline { 2 - 5 } & SUPERF. & 2 METROS & CABINE DO MOTORISTA & \\
\hline & & & & \\
\hline & & & & \\
\hline & & & & \\
\hline & & & & \\
\hline & & & & \\
\hline
\end{tabular}

CROQUIS DA MONITORAÇÃO NO VEICULO

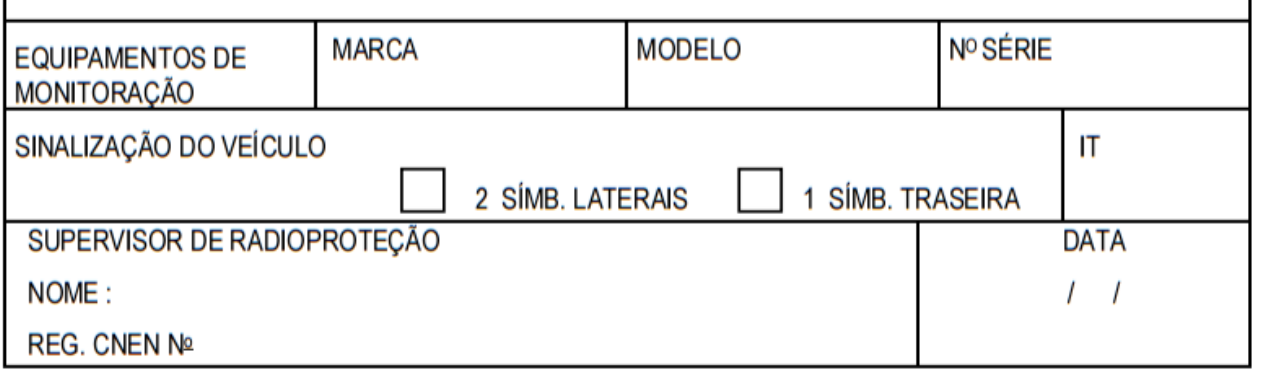

*Disponível em: <http://appasp.cnen.gov.br/seguranca/normas/pdf/Nrm501.pdf> 
ANEXO B*

Declaração do Expedidor

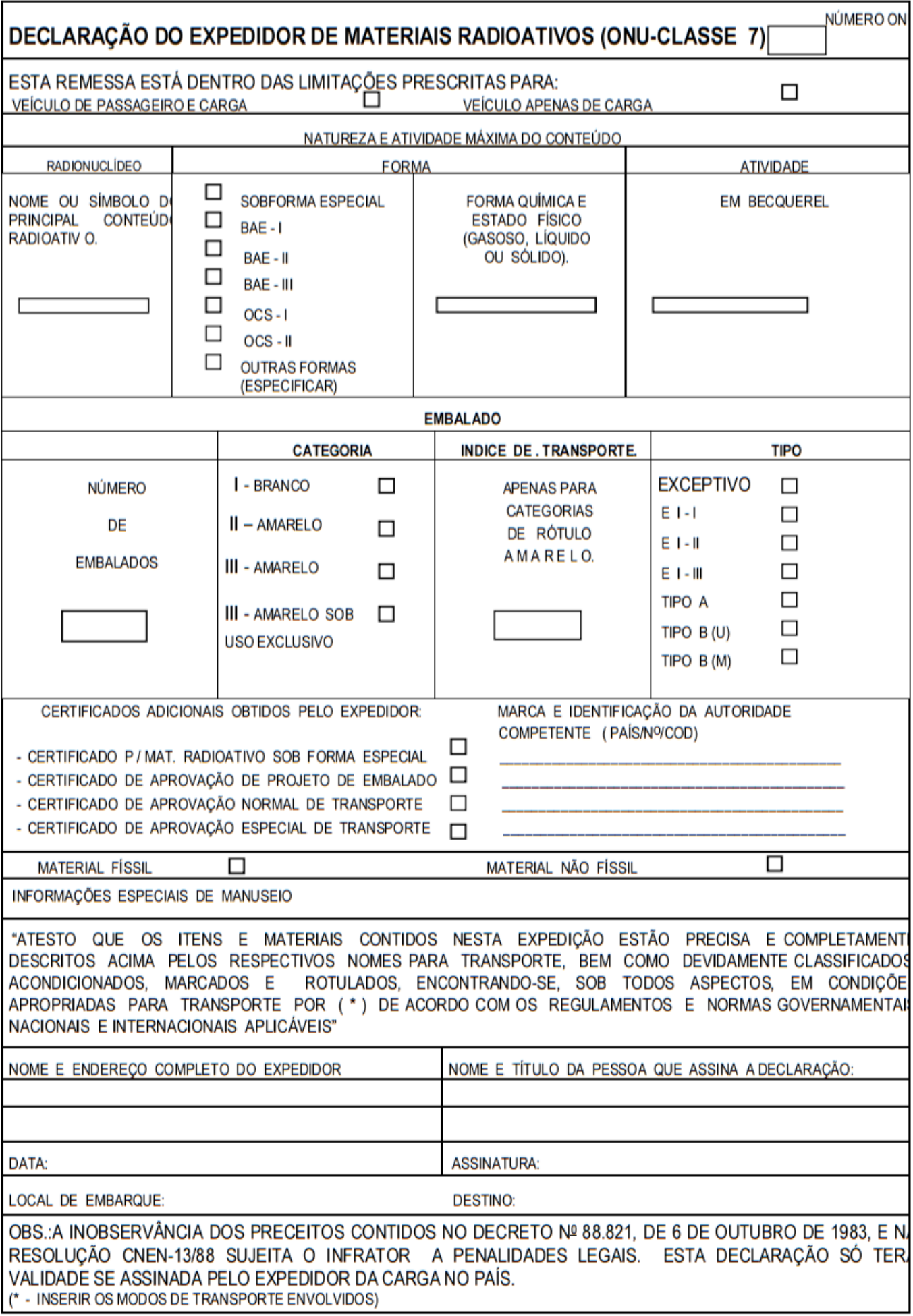

*Disponível em: <http://appasp.cnen.gov.br/seguranca/normas/pdf/Nrm501.pdf> 
Wagner J, Faiman CJS. Exposição ocupacional no transporte de materiais radioativos.

ANEXO C**

Tabela de Dados Experimentais

\begin{tabular}{|c|c|c|c|c|c|c|c|}
\hline DATA & ISÓTOPO & $\begin{array}{c}\text { ATIVIDADE } \\
\text { RECEBIDA } \\
\text { (mCi) }\end{array}$ & $\begin{array}{l}\text { ATIVIDADE } \\
\text { RECEBIDA } \\
\text { (MBq) }\end{array}$ & $\begin{array}{l}\text { EXPOSIÇÃO } \\
\text { CALCULADA } \\
(\mathrm{mSV} / \mathrm{h})\end{array}$ & $\begin{array}{c}\text { EXPOSIÇÃo } \\
\text { MEDIDA } \\
\text { (mSv/h) }\end{array}$ & $\begin{array}{l}\text { ESTIMATIVA DOSE } \\
\text { VIAGEM DE } 45 \\
\text { MINUTOS (mSv) }\end{array}$ & $\begin{array}{l}\text { SOMATÓRIO } \\
\text { MENSAL } \\
\text { (mSv) }\end{array}$ \\
\hline $11 / 10 / 2016$ & $\mid-131$ & 114 & 4218 & 0,3222552 & 0,0076 & 0,0057 & \multirow{54}{*}{0,3874875} \\
\hline $11 / 10 / 2016$ & $\mid-131$ & 113 & 4181 & 0,3194284 & 0,0079 & 0,005925 & \\
\hline $13 / 10 / 2016$ & $F-18$ & 398 & 14726 & 2,7257826 & 0,0052 & 0,0039 & \\
\hline $13 / 10 / 2016$ & F-18 & 284 & 10508 & 1,9450308 & 0,0037 & 0,002775 & \\
\hline $13 / 10 / 2016$ & Tc-99m & 2000 & 74000 & 2,4938 & 0,0202 & 0,01515 & \\
\hline $13 / 10 / 2016$ & Tc-99m & 600 & 22200 & 0,74814 & 0,0040 & 0,0030075 & \\
\hline $14 / 10 / 2016$ & $\mathrm{~F}-18$ & 420 & 15540 & 2,876454 & 0,0048 & 0,0036 & \\
\hline $14 / 10 / 2016$ & $F-18$ & 292 & 10804 & 1,9998204 & 0,0046 & 0,00345 & \\
\hline $14 / 10 / 2016$ & Tc-99m & 2800 & 103600 & 3,49132 & 0,0287 & 0,021525 & \\
\hline $17 / 10 / 2016$ & $F-18$ & 161 & 5957 & 1,1026407 & 0,0115 & 0,008625 & \\
\hline 18/10/2016 & $\mathrm{F}-18$ & 247 & 9139 & 1,6916289 & 0,0047 & 0,003525 & \\
\hline 18/10/2016 & $\mathrm{F}-18$ & 137 & 5069 & 0,9382719 & 0,0026 & 0,00195 & \\
\hline 18/10/2016 & $\mid-131$ & 55 & 2035 & 0,155474 & 0,0107 & 0,008025 & \\
\hline 18/10/2016 & $\mid-131$ & 114 & 4218 & 0,3222552 & 0,0106 & 0,00795 & \\
\hline 18/10/2016 & $\mid-131$ & 113 & 4181 & 0,3194284 & 0,0114 & 0,00855 & \\
\hline $18 / 10 / 2016$ & Lu-177 & 205 & 7585 & 0,05791906 & 0,0013 & 0,000975 & \\
\hline $20 / 10 / 2016$ & $\mathrm{~F}-18$ & 33,2 & 1228,4 & 0,22737684 & 0,0029 & 0,0021375 & \\
\hline 20/10/2016 & Tc-99m & 2000 & 74000 & 2,4938 & 0,0227 & 0,017025 & \\
\hline $21 / 10 / 2016$ & $\mathrm{~F}-18$ & 248 & 9176 & 1,6984776 & 0,0022 & 0,001635 & \\
\hline $22 / 10 / 2016$ & $\mathrm{~F}-18$ & 60 & 2220 & 0,410922 & 0,0039 & 0,002955 & \\
\hline $22 / 10 / 2016$ & Tc-99m & 2800 & 103600 & 3,49132 & 0,0292 & 0,0219 & \\
\hline $22 / 10 / 2016$ & Ga-67 & 10 & 370 & 0,144115 & 0,0017 & 0,0012525 & \\
\hline $24 / 10 / 2016$ & $F-18$ & 258 & 9546 & 1,7669646 & 0,0038 & 0,00288 & \\
\hline $24 / 10 / 2016$ & $\mathrm{~F}-18$ & 67,3 & 2490,1 & 0,46091751 & 0,0068 & 0,00513 & \\
\hline $24 / 10 / 2016$ & $\mid-131$ & 30 & 1110 & 0,084804 & 0,0143 & 0,010725 & \\
\hline $25 / 10 / 2016$ & $F-18$ & 242 & 8954 & 1,6573854 & 0,0029 & 0,002175 & \\
\hline $25 / 10 / 2016$ & F-18 & 280 & 10360 & 1,917636 & 0,0045 & 0,003375 & \\
\hline $25 / 10 / 2016$ & $\mid-131$ & 164 & 6068 & 0,4635952 & 0,0115 & 0,008625 & \\
\hline 25/10/2016 & $\mid-131$ & 114 & 4218 & 0,3222552 & 0,0078 & 0,00585 & \\
\hline 26/10/2016 & $\mathrm{F}-18$ & 240 & 8880 & 1,643688 & 0,0024 & 0,00177 & \\
\hline 26/10/2016 & $F-18$ & 203 & 7511 & 1,3902861 & 0,0021 & 0,0015975 & \\
\hline $27 / 10 / 2016$ & $\mathrm{~F}-18$ & 292 & 10804 & 1,9998204 & 0,0161 & 0,012075 & \\
\hline 28/10/2016 & $F-18$ & 260 & 9620 & 1,780662 & 0,0045 & 0,003375 & \\
\hline $28 / 10 / 2016$ & $\mathrm{Ga}-67$ & & 0 & 0 & 0,0018 & 0,0013725 & \\
\hline 28/10/2016 & Tc-99m & 2000 & 74000 & 2,4938 & 0,0183 & 0,013725 & \\
\hline 29/10/2016 & Tc-99m & 2800 & 103600 & 3,49132 & 0,0287 & 0,021525 & \\
\hline $31 / 10 / 2016$ & $F-18$ & 223 & 8251 & 1,5272601 & 0,0039 & 0,002955 & \\
\hline $31 / 10 / 2016$ & $\mathrm{~F}-18$ & 224 & 8288 & 1,5341088 & 0,0034 & 0,00255 & \\
\hline $31 / 10 / 2016$ & I-131 & 55 & 2035 & 0,155474 & 0,0056 & 0,0042 & \\
\hline $31 / 10 / 2016$ & $\mid-131$ & 114 & 4218 & 0,3222552 & 0,0078 & 0,00585 & \\
\hline $31 / 10 / 2016$ & Lu-177 & 5 & 185 & 0,00141266 & 0,0002 & 0,000135 & \\
\hline $01 / 11 / 2016$ & $\mathrm{~F}-18$ & 225 & 8325 & 1,5409575 & 0,0212 & 0,0159 & \\
\hline $03 / 11 / 2016$ & $\mathrm{~F}-18$ & 177 & 6549 & 1,2122199 & 0,0033 & 0,002475 & \\
\hline $04 / 11 / 2016$ & $\mathrm{~F}-18$ & 59 & 2183 & 0,4040733 & 0,0073 & 0,00549 & \\
\hline $04 / 11 / 2016$ & Tc-99m & 2000 & 74000 & 2,4938 & 0,0197 & 0,014775 & \\
\hline $05 / 11 / 2016$ & Ga-67 & & 0 & 0 & 0,0009 & 0,0006525 & \\
\hline 05/11/2016 & $\mathrm{F}-18$ & 27,5 & 1017,5 & 0,18833925 & 0,0028 & 0,002115 & \\
\hline $05 / 11 / 2016$ & Tc-99m & 2800 & 103600 & 3,49132 & 0,0346 & 0,02595 & \\
\hline $07 / 11 / 2016$ & $\mathrm{~F}-18$ & 197 & 7289 & 1,3491939 & 0,0032 & 0,0024 & \\
\hline $07 / 11 / 2016$ & $\mathrm{~F}-18$ & 258 & 9546 & 1,7669646 & 0,0020 & 0,00147 & \\
\hline 08/11/2016 & $F-18$ & 219 & 8103 & 1,4998653 & 0,0032 & 0,00237 & \\
\hline $08 / 11 / 2016$ & $\mathrm{~F}-18$ & 223 & 8251 & 1,5272601 & 0,0042 & 0,00315 & \\
\hline 09/11/2016 & $F-18$ & 270 & 9990 & 1,849149 & 0,0196 & 0,0147 & \\
\hline $09 / 11 / 2016$ & $\mathrm{~F}-18$ & 284 & 10508 & 1,9450308 & 0,0188 & 0,0141 & \\
\hline
\end{tabular}


Wagner J, Faiman CJS. Exposição ocupacional no transporte de materiais radioativos.

\begin{tabular}{|c|c|c|c|c|c|c|c|}
\hline 10/11/2016 & $F-18$ & 314 & 11618 & 2,1504918 & 0,0043 & 0,003225 & \\
\hline 10/11/2016 & $\mathrm{F}-18$ & 311 & 11507 & 2,1299457 & 0,0042 & 0,0031125 & \\
\hline $10 / 11 / 2016$ & Tc-99m & 2000 & 74000 & 2,4938 & 0,0189 & 0,014175 & \\
\hline $11 / 11 / 2016$ & Tc-99m & 2800 & 103600 & 3,49132 & 0,0276 & 0,0207 & \multirow{51}{*}{0,3058575} \\
\hline $11 / 11 / 2016$ & $F-18$ & 303 & 11211 & 2,0751561 & 0,0054 & 0,00405 & \\
\hline $11 / 11 / 2016$ & F-18 & 173 & 6401 & 1,1848251 & 0,0036 & 0,0027 & \\
\hline $11 / 11 / 2016$ & $\mathrm{~F}-18$ & 91,6 & 3389,2 & 0,62734092 & 0,0024 & 0,0017625 & \\
\hline 14/11/2016 & |-131 & 55 & 2035 & 0,155474 & 0,0021 & 0,001575 & \\
\hline $15 / 11 / 2016$ & $\mathrm{I}-131$ & 114 & 4218 & 0,3222552 & 0,0076 & 0,0057 & \\
\hline $15 / 11 / 2016$ & I-131 & 163 & 6031 & 0,4607684 & 0,0114 & 0,00855 & \\
\hline 16/11/2016 & F-18 & 202 & 7474 & 1,3834374 & 0,0170 & 0,01275 & \\
\hline $16 / 11 / 2016$ & F-18 & 185 & 6845 & 1,2670095 & 0,0106 & 0,00795 & \\
\hline $17 / 11 / 2016$ & $\mathrm{~F}-18$ & 140 & 5180 & 0,958818 & 0,0073 & 0,005475 & \\
\hline $17 / 11 / 2016$ & $\mathrm{~F}-18$ & 177 & 6549 & 1,2122199 & 0,0150 & 0,01125 & \\
\hline $17 / 11 / 2016$ & $F-18$ & 115 & 4255 & 0,7876005 & 0,0106 & 0,00795 & \\
\hline $17 / 11 / 2016$ & F-18 & 164 & 6068 & 1,1231868 & 0,0029 & 0,002175 & \\
\hline $17 / 11 / 2016$ & Tc-99m & 2000 & 74000 & 2,4938 & 0,0200 & 0,015 & \\
\hline $18 / 11 / 2016$ & $F-18$ & 229 & 8473 & 1,5683523 & 0,0046 & 0,003465 & \\
\hline $18 / 11 / 2016$ & $\mathrm{~F}-18$ & 133 & 4921 & 0,9108771 & 0,0022 & 0,0016725 & \\
\hline $18 / 11 / 2016$ & $\mathrm{~F}-18$ & 63 & 2331 & 0,4314681 & 0,0048 & 0,0036 & \\
\hline 18/11/2016 & F-18 & 273 & 10101 & 1,8696951 & 0,0174 & 0,01305 & \\
\hline 19/11/2016 & Tc-99m & 2800 & 103600 & 3,49132 & 0,0284 & 0,0213 & \\
\hline $20 / 11 / 2016$ & TI-201 & 6 & 222 & 0,00526584 & 0,0046 & 0,00345 & \\
\hline $21 / 11 / 2016$ & $\mid-131$ & 55 & 2035 & 0,155474 & 0,0184 & 0,0138 & \\
\hline $22 / 11 / 2016$ & I-131 & 114 & 4218 & 0,3222552 & 0,0073 & 0,005475 & \\
\hline $22 / 11 / 2016$ & I-131 & 163 & 6031 & 0,4607684 & 0,0109 & 0,008175 & \\
\hline $23 / 11 / 2016$ & F-18 & 158 & 5846 & 1,0820946 & 0,0029 & 0,002175 & \\
\hline 23/11/2016 & $F-18$ & 300 & 11100 & 2,05461 & 0,0035 & 0,00264 & \\
\hline $24 / 11 / 2016$ & Tc-99m & 2000 & 74000 & 2,4938 & 0,0197 & 0,014775 & \\
\hline $25 / 11 / 2016$ & Tc-99m & 2800 & 103600 & 3,49132 & 0,0284 & 0,0213 & \\
\hline 25/11/2016 & F-18 & 284 & 10508 & 1,9450308 & 0,0022 & 0,0016125 & \\
\hline $28 / 11 / 2016$ & $\mathrm{~F}-18$ & 120,3 & 4451,1 & 0,82389861 & 0,0052 & 0,0038625 & \\
\hline 28/11/2016 & $F-18$ & 40 & 1480 & 0,273948 & 0,0012 & 0,0008775 & \\
\hline $30 / 11 / 2016$ & $F-18$ & 103,9 & 3844,3 & 0,71157993 & 0,0053 & 0,0039525 & \\
\hline $01 / 12 / 2016$ & $\mathrm{~F}-18$ & 288 & 10656 & 1,9724256 & 0,0017 & 0,0012975 & \\
\hline $01 / 12 / 2016$ & Tc-99m & 1000 & 37000 & 1,2469 & 0,0200 & 0,015 & \\
\hline $02 / 12 / 2016$ & F-18 & 254 & 9398 & 1,7395698 & 0,0014 & 0,0010275 & \\
\hline $02 / 12 / 2016$ & $\mathrm{~F}-18$ & 160 & 5920 & 1,095792 & 0,0010 & 0,00072 & \\
\hline $02 / 12 / 2016$ & F-18 & 85 & 3145 & 0,5821395 & 0,0013 & 0,0009675 & \\
\hline $03 / 12 / 2016$ & $\mathrm{~F}-18$ & 140 & 5180 & 0,958818 & 0,0063 & 0,00471 & \\
\hline $05 / 12 / 2016$ & $\mathrm{~F}-18$ & 190 & 7030 & 1,301253 & 0,0019 & 0,0014025 & \\
\hline $05 / 12 / 2016$ & F-18 & 212 & 7844 & 1,4519244 & 0,0021 & 0,0015525 & \\
\hline $06 / 12 / 2016$ & F-18 & 153 & 5661 & 1,0478511 & 0,0013 & 0,0009675 & \\
\hline $06 / 12 / 2016$ & $\mathrm{~F}-18$ & 156 & 5772 & 1,0683972 & 0,0016 & 0,00117 & \\
\hline $06 / 12 / 2016$ & $\mid-131$ & 164 & 6068 & 0,4635952 & 0,0106 & 0,00795 & \\
\hline $06 / 12 / 2016$ & $\mid-131$ & 163 & 6031 & 0,4607684 & 0,0117 & 0,008775 & \\
\hline $06 / 12 / 2016$ & $\mid-131$ & 164 & 6068 & 0,4635952 & 0,0103 & 0,007725 & \\
\hline $06 / 12 / 2016$ & $\mathrm{I}-131$ & 211 & 7807 & 0,5964548 & 0,0150 & 0,01125 & \\
\hline $07 / 12 / 2016$ & $\mathrm{~F}-18$ & 404 & 14948 & 2,7668748 & 0,0025 & 0,0018375 & \\
\hline $07 / 12 / 2016$ & $\mathrm{~F}-18$ & 406 & 15022 & 2,7805722 & 0,0030 & 0,0022275 & \\
\hline $08 / 12 / 2016$ & F-18 & 208 & 7696 & 1,4245296 & 0,0018 & 0,00135 & \\
\hline $08 / 12 / 2016$ & $\mathrm{~F}-18$ & 209 & 7733 & 1,4313783 & 0,0020 & 0,0014625 & \\
\hline $09 / 12 / 2016$ & F-18 & 220 & 8140 & 1,506714 & 0,0011 & 0,0008175 & \\
\hline $09 / 12 / 2016$ & $\mathrm{~F}-18$ & 220 & 8140 & 1,506714 & 0,0012 & 0,0008775 & \\
\hline $11 / 12 / 2016$ & Tc-99m & 2800 & 103600 & 3,49132 & 0,0285 & 0,021375 & \\
\hline $12 / 12 / 2016$ & F-18 & 71,9 & 2660,3 & 0,49242153 & 0,0024 & 0,00177 & \\
\hline $12 / 12 / 2016$ & $\mid-131$ & 50 & 1850 & 0,14134 & 0,0051 & 0,003855 & \\
\hline $12 / 12 / 2016$ & I-131 & 85 & 3145 & 0,240278 & 0,0080 & 0,0059625 & \\
\hline 13/12/2016 & $\mathrm{F}-18$ & 293 & 10841 & 2,0066691 & 0,0032 & 0,002385 & \\
\hline $13 / 12 / 2016$ & $\mid-131$ & 163 & 6031 & 0,4607684 & 0,0104 & 0,0078 & \\
\hline $13 / 12 / 2016$ & $\mid-131$ & 164 & 6068 & 0,4635952 & 0,0114 & 0,00855 & \\
\hline 13/12/2016 & |-131 & 164 & 6068 & 0,4635952 & 0,0109 & 0,008175 & \\
\hline
\end{tabular}




\begin{tabular}{|c|c|c|c|c|c|c|c|}
\hline $13 / 12 / 2016$ & I-131 & 113 & 4181 & 0,3194284 & 0,0078 & 0,00585 & \multirow{10}{*}{0,1170525} \\
\hline $13 / 12 / 2016$ & $1-131$ & 114 & 4218 & 0,3222552 & 0,0081 & 0,006075 & \\
\hline $14 / 12 / 2016$ & F-18 & 218 & 8066 & 1,4930166 & 0,0010 & 0,000735 & \\
\hline $14 / 12 / 2016$ & F-18 & 220 & 8140 & 1,506714 & 0,0014 & 0,0010725 & \\
\hline $15 / 12 / 2016$ & $F-18$ & 236 & 8732 & 1,6162932 & 0,0117 & 0,008775 & \\
\hline $17 / 12 / 2016$ & F-18 & 191 & 7067 & 1,3081017 & 0,0065 & 0,0048675 & \\
\hline $17 / 12 / 2016$ & Tc-99m & 2800 & 103600 & 3,49132 & 0,0260 & 0,0195 & \\
\hline 19/12/2016 & F-18 & 214 & 7918 & 1,4656218 & 0,0070 & 0,005265 & \\
\hline $20 / 12 / 2016$ & $F-18$ & 57,8 & 2138,6 & 0,39585486 & 0,0022 & 0,00165 & \\
\hline $20 / 12 / 2016$ & $F-18$ & 159 & 5883 & 1,0889433 & 0,0045 & 0,00339 & \\
\hline
\end{tabular}

**As remessas destacadas em vermelho indicam outliers, pois são dados muito divergentes à grande maioria ou inconsistentes.

Wagner J, Faiman CJS. Occupational exposure in the transportation of radioactive materials. Saúde, Ética \& Justiça. 2017;22(1):9-25.

ABSTRACT: The pacific use of radiation has been growing since the second half of the $20^{\text {th }}$ century, with applications in fields as industry, agriculture, medicine and to produce nuclear energy. Utilizing data from measures of the radiation emitted from expedited material and statistical projections of hypothetical exposition to radiation, this study addressed verifying if the occupational exposure to radiation which drivers who transport radioactive material are subjected is according to the limits determined by the regulation. Thus, it would be possible to estimate the risk that workers in this occupation exceed the limit imposed by the National Nuclear Energy Commission (CNEN) for the occupationally exposed individual and consequently are subject to present the consequences of undue radiation exposure for their health. Based on our measurements and projections, made from material delivery data to hospitals in São Paulo, we find that it is likely that drivers who are currently in the activity exceed the limits of monthly exposure advocated for the preservation of their health.

KEY WORDS: Occupational Exposure; Radiation Exposure; Regulations.

\section{AGRADECIMENTOS}

À Danielle Pereira Wiecek pela coordenação e elaboração da coleta de dados para este trabalho (Física em Medicina);

À equipe de biomédicos e radiofarmacêuticos do Serviço de Medicina Nuclear do Hospital Israelita Albert Einstein, SP.

\section{REFERÊNCIAS}

1. Cardoso EM. Apostila educativa - Aplicações da energia nuclear [Internet]. Rio de Janeiro: Comissão Nacional de Energia Nuclear [acesso em 2016 set. 19]. Disponível em: http://www.cnen.gov.br/images/cnen/documentos/ educativo/aplicacoes-da-energia-nuclear.pdf

2. Romano ACP, Najar CSV, Ribeiro JVL, Dias MP, Rocha RS. Agência Internacional de Energia Atômica (AIEA): Guia de Estudos [Internet]. Brasília, DF; 2014 [acesso em 2016 set. 19]. Disponível em: http://sinus.org.br/2014/wp-content/ uploads/2013/11/AIEA-Guia-Online.pdf

3. Rodrigues DL. Impacto Radiológico devido ao transporte de Radiofármacos do IPEN - CNEN/SP [tese]. São Paulo: Universidade de São Paulo. Instituto de Pesquisas Energéticas e Nucleares; 2009.

4. Comissão Nacional de Energia Nuclear (CNEN). Transporte de materiais radioativos [Internet]. Brasília, DF; 1988 [acesso em 2016 set. 19]. Disponível em: http://appasp.cnen. gov.br/seguranca/normas/pdf/Nrm501.pdf

5. Ministério da Ciência, Tecnologia, Inovações e Comunicações (MCTIC), Comissão Nacional de Energia Nuclear. Transporte de material radioativo [Internet]. Brasília, DF; 2015 [acesso em 2016 set. 20]. Disponível em: http://www.cnen.gov.br/ transporte-de-material-radioativo

6. Yamaga LYI, Cunha ML, Wagner J, Thom AF, Daniel MM, Funari MBG. Valor diagnóstico da tomografia por emissão de pósitrons / tomografia computadorizada (PET-CT) com flúor-18 fluordeoxiglicose (FDG-18F) em pacientes com carcinoma diferenciado da tireóide, níveis séricos de tireoglobulina elevados e pesquisa de corpo inteiro com iodo negativa. Arq Bras Endocrinol Metab. 2007;51(4):581-6. DOI: http://dx.doi.org/10.1590/S0004-27302007000400012

7. Araújo EB, Lavinas T, Colturato MT, Mengatti J. Garantia da qualidade aplicada à produção de radiofármacos. Rev Bras Cienc Farm. 2008;44(1):1-12. DOI: http://dx.doi. org/10.1590/S1516-93322008000100002

8. International Atomic Energy Agency (IAEA). Transporte de Materiais Radioativos [Internet]. Viena; 2015 [acesso em 2016 set. 21]. Disponível em: http://www.iaea.org/inis/ collection/NCLCollectionStore/_Public/45/073/45073474. pdf 